\title{
O ESTUDO DOS CRISTÃOS-NOVOS NO BRASIL COLÔNIA SOBRE A ÓTICA DAS ESCOLAS ISRAELITAS: ESTUDO DE CASO
}

\section{THE STUDY OF THE NEW-CHRISTIANS IN THE COLONIAL BRAZIL UNDER THE VIEW OF THE ISRAELI SCHOOLS: CASE STUDY}

Helena Ragusa ${ }^{1}$

\begin{abstract}
RESUMO: Trata-se do modo como se dá o ensino de História numa escola de origem judaica, a qual aqui iremos chamar de Cheder, localizada na cidade de São Paulo. Enfatizam-se dois materiais: livros didáticos utilizados nas escolas não judaicas. A escola judaica (início século XIX), apresentava-se como uma forma de preservação da cultura, da memória e da identidade judaica que faziam questão de manter. Em se tratando das disciplinas ligadas ao ensino do judaísmo, essas ocorrem, exceto pelo ensino da língua hebraica, externamente daquelas que compreendem o currículo oficial, e, dessa forma, não se limitam apenas ao currículo judaico; não necessariamente implicam na obrigatoriedade do ensino religioso; a escrita da história em torno dos cristãos-novos nos textos aqui apresentados, demonstra a todo o momento o quanto esses agentes estavam integrados nas sociedades em que se inseriram, criando redes de negociação e sociabilidade com as populações locais, mesclando-se a elas, ocupando cargos de confiança e criando mecanismos de sobrevivência.
\end{abstract}

Palavras-Chave: Escola Judaica. História e Ensino. Material didático. São Paulo

\begin{abstract}
In this study, it is our aim to call attention to the way the teaching of History is done in a school of Jewish origin, which herein shall be called CHEDER, and it is located in the city of Sao Paulo. Our emphasis will be placed on two materials: the textbooks used in the non-Jewish schools. The school (beginning of the XX Century) presented itself as a way to maintain the cultural, the memory and the Jewish identity they wanted to preserve. In our first studies, it was possible to see that, concerning the disciplines related to the teaching of the Judaism, those occurred, with the exception of the teaching of the Hebrew language, apart from the ones in the official curriculum, thus not being limited to the Jewish curriculum only, and not necessarily involving the obligation of the religious teachings; it is also noted that, rather to the contrary of a submission and victimization, the writing about the New-Christians in the texts presented herein, show consistently how much these agents were integrated in the societies they had been inserted, developing trading nets and social relationships with the local population, mingling with them, occcupying positions of trust and creating mechanisms of survival.
\end{abstract}

Keywords: School. History and Teaching. Textbooks. São Paulo.

\footnotetext{
${ }^{1}$ Universidade Estadual de Ponto Grossa. Mestre do curso de História Social da Universidade Estadual de Londrina.
} 


\section{Introdução}

"A história da educação judaica no Brasil ainda está por ser feita" (FALBEL, 2008, p. 321). Essa é a constatação de Nachman Falbel em seu estudo sobre os judeus no Brasil, como um tema que segundo ele, "permanece em aberto aos pesquisadores".

Há milênios na história do povo judeu a educação teve e tem um papel fundamental na construção e na preservação de uma identidade coletiva, uma espécie de continuidade do Judaísmo (TRZONOWICZ, 2006). Desde que chegaram ao Brasil, os judeus demonstraram grande preocupação com o futuro de seus filhos, e nesse sentido a escola se transforma num espaço para a transmissão da cultura, da religião e tradições judaicas (MANDELERT, 2005: 84).

As primeiras escolas judaicas já existiam na Babilônia no período do Segundo Templo, conforme nos aponta Sergio Alberto Feldman (2008:225), o ensino judaico perpetuou-se por séculos entre os judeus europeus, tanto os de origem sefaradi, quanto os ashkenazi.

Até o século XIX, podemos dizer que os judeus viviam de acordo com seus próprios princípios e valores, constituindo uma vida que dissociava-se daquela vivida pelos cristãos. Tinham suas instituições jurídicas, que eles mesmos criaram e seguiram, "não compartilhavam da cultura hegemônica da região que habitavam". Quanto sua relação com o Estado, somente quando dizia respeito à coleta de impostos e à organização e defesa do território é que o mesmo lhes dava a atenção (GRINBERG, 1997, s/p).

Este cenário mudou de fato, após a Revolução Francesa, onde para conseguirem o reconhecimento de cidadãos precisavam abdicar de seu modo de vida, passando então a integrarem e a compartilharem dos mesmos direitos e deveres da sociedade a qual passaram a conviver, processo esse chamado de Emancipação dos judeus (GRINBERG, 1997, s/p). A partir de então, a identidade judaica passou por uma reconfiguração, tendo em vista que assim como nos dias atuais, já naquele período, "as barreiras institucionais que até então filtravam e limitavam a influência do meio externo sobre a identidade judaica foram desaparecendo gradativamente" (MANDELERT, 2005, p. 73). 
Foi nesse contexto que se deu a criação das escolas judaicas, com o intuito de preservar a cultura, a memória e a identidade, quando o judeu pôde optar entre sê-lo ou não. Dessa forma:

\begin{abstract}
A questão da transmissão de valores passou a ocupar posição fundamental (embora isto não queira dizer que não ocupasse antes; ela apenas foi investida de outros sentidos). Não por acaso, o surgimento de escolas judaicas, isto é, escolas que cumpram o programa normal de seu país de localização e ainda contemplem temas especificamente judaicos (GRINBERG, 1997, s/p).
\end{abstract}

Importante ressaltar que essa nova configuração pela qual passou a identidade judaica, refletiu não só na estrutura religiosa familiar, como também na própria família, uma vez que não se tratava mais de um grupo "homogêneo". Desde essa época o modo como deve ocorrer à educação dentro da escola judaica, tem sido o cerne das discussões e debates entre os diversos membros das comunidades, entidades e escolas voltados para essa questão e que buscam o melhor modelo a ser seguido:

A responsabilidade com a educação judaica pertence à família judaica. Ela não foi transferida totalmente para as escolas. Foi ampliada. Faz-se necessária uma comunicação direta e harmônica para que as razões que levaram historicamente ao surgimento das escolas judaicas sejam sempre levadas em consideração na fixação dos objetivos (PINTO, 2009, p. 238).

Num estudo sobre a comunidade judaica em São Paulo, realizado no final da década de 1970, Henrique Rattner, constatava a existência de onze escolas judaicas integrais, onde os alunos recebiam além do ensino oficial, duas a três horas por dia de ensinamentos vinculados à história judaica, da bíblia, das tradições e do hebraico. Ali, o autor já apontava para um grande crescimento do número de alunos, além de uma ampliação nos currículos que introduziam o curso ginasial e colegial, resultando, segundo ele, na permanência de muitas crianças judias que desde muito cedo ingressavam nas escolas (RATTNER, 1977, p. 65).

O colégio Renascença teria sido a primeira escola do Estado de São Paulo a oferecer o diploma de primário junto ao ensino judaico e que definiu o 
estabelecimento de uma comunidade organizada na grande metrópole. Fundada por judeus oriundos principalmente da Europa Oriental, a escola surgiu no ano de 1922 em uma pequena casa alugada sendo também, a primeira escola efetivamente hebraico-israelita de SP, que combinava o currículo oficial com um ensino judaico formal (CYTRYNOWICZ; ZUQUIN, 1997, p. 25). Ao decidir fundar sua primeira escola, a comunidade fazia questão que seus filhos conhecessem o mundo e a cultura judaica da Europa Oriental, da Torá, do Talmud, do ídiche e sua literatura do hebraico, do iluminismo, do sionismo, enfim, uma tradição que não deveria ser interrompida (CYTRYNOWICZ; ZUQUIN, 1997, p. 48).

A manutenção dessa tradição é ainda uma prioridade, para os judeus que escolheram viver de acordo com os princípios do judaísmo, fator esse que, levou à criação das primeiras escolas judaicas no Brasil. Fundadas por professores pioneiros, ao lado de poucos pais, empenhados em garantir a educação israelita (FALBEL, 2008, p. 758):

As escolas judaicas atuais, incluindo seus estudos seculares, são fruto do processo de integração à sociedade, por parte dos judeus nas suas respectivas diásporas, que vão trazendo e reproduzindo suas próprias experiências para as próximas gerações (TRZONOWICZ, 2006, p. 41).

Importante ressaltar neste contexto a atuação do rabino Isaias Raffalovich descrita por Falbel (2008, p. 335), a respeito de sua atuação enquanto representante oficial da J. C. A., tanto na organização de instituições de ajuda ao imigrante, como na formação da rede escolar judaica no Brasil. Segundo o autor, tendo chegado ao Brasil na década de 1923 e se deslocado para diversas regiões do país, o rabino contribuiu para a formação de diversas escolas judaicas, principalmente fora dos grandes centros urbanos que na época, já haviam constituído suas primeiras escolas, como foi o caso do Estado de São Paulo.

De acordo com Alberto Samuel Milkewit Trzonowicz, em seu estudo recente sobre famílias e escolas judaicas no Estado, os judeus vem construindo um sistema bastante complexo, ou seja, diversificado em relação às organizações e serviços criados por eles que ocorrem em diferentes contextos. Um deles seriam as escolas, criadas por grande parte dos imigrantes poloneses, 
expostos "à diversidade de alternativas possíveis à educação judaica, bem como à integração dos estudos judaicos e seculares" (TRZONOWICZ, 2006, p. 41).

São quatro modelos de escolas judaicas consideradas tradicionais, duas ortodoxas, e três Yeschivot ${ }^{2}$, além de várias outras que formam um total de 4400 alunos da Educação Infantil ao Ensino Médio. Mesmo diferenciando-se quanto às tendências e grupo comunitário fundador, além da influência composta com as orientações nacionais brasileiras, existe sobre elas, uma forte influência da organização escolar do Estado de Israel sobre a educação judaica paulista (TRZONOWICZ, 2006, p. 31-44).

Trata-se de uma identidade, como chamou Roney Cytrynowicz, em seu estudo acerca da comunidade judaica no Brasil entre 1930 e 1940, hebraico brasileira ou hebreu-brasileira:

\begin{abstract}
A definição - a "invenção" - de uma identidade hebraico brasileira ou hebreu-brasileira foi constante no processo de implantação da "colônia israelita" em São Paulo a partir dos anos 1910. De um lado essa identidade hifenizada era adequada a um projeto de inserção e de nacionalização da própria colônia israelita, que era brasileira e, hífen, algo mais. Do outro lado, era adequada como resposta a uma sociedade que discutia intensamente, entre os anos 1920 e 1940, seu caráter nacional, homogeneidade étnica, projeto nacional, imigração e povoamento. (CYTRYNOWICZ, 2005, p. 309).
\end{abstract}

Tal constatação, embora realizada sobre um período diferente daquele abordado por nós, não parece destoar daquilo que vimos tentando mostra desde o início desse capítulo, ou seja, o esforço das escolas judaicas, em nacionalizarem-se e conseguirem de certa forma, manterem o ensino da língua hebraica e também dos conteúdos judaicos, conforme nos aponta o autor.

\title{
1. O cristão-novo na obra de Renato Mezan: alguns apontamentos
}

Começamos nossa análise pela obra organizada pelo autor Renato Mezan, Caminhos do Povo Judeu, mais especificamente o III volume, que assim como o

\footnotetext{
2 Institutos para o ensino da Torah e das leis judaicas, local onde se ensina os preceitos e mandamentos da religião judaica (ASHERI, 1995: 258).
} 
IV volume foi publicado na década de 1970, pelo Conselho de Ensino da Federação Israelita do Estado de São Paulo, tendo grande adesão dentre as escolas judaicas do Brasil. O livro faz parte de uma série organizada para o curso de História Judaica oferecido pelas escolas judaicas, mas que na época foi criada por uma equipe de professores coordenados pela professora Rifka Berezin, membro da Comissão de Chinuch da Organização Sionista do Brasil.

Apesar de voltado para o curso específico de História Judaica, o livro também possui inúmeras referências à História Geral, não estando, portanto, desvinculado do conhecimento histórico que abarca as estruturas das demais sociedades e dos períodos que a compõe, como a Antiguidade e o chamado período de Idade Média.

Nossa análise inicia com o capítulo 7, destinado aos judeus da Península Ibérica entre os séculos XIII e XV, quando se vem obrigados a passar pelo processo de conversão na Espanha:

Não é difícil compreender que muitos destes cristãos-novos eram cristãos só aparentemente, pois haviam aceito o cristianismo somente sob a pressão de perseguições. Mas a Igreja jamais permitira que, uma vez batizada, uma pessoa se afastasse do cristianismo para retornar à sua religião anterior (MEZAN, 1974, p. 183).

Aqui se denotam duas preocupações do autor em relação a como tratar a temática: a primeira delas seria deixar claro para o leitor que os judeus ali convertidos, e que naquele momento passaram a ser nomeados de cristãosnovos, não eram de fato cristãos. Ao utilizar da expressão aparentemente referindo-se aos judeus que tornaram-se cristãos, o autor dá indícios de que tratava-se apenas de um ato de obediência, de sobrevivência, tendo em vista o poder que a Igreja Católica representava naquele período. Nesse discurso, fica clara também a postura da Igreja frente a esses agentes, assim como a complexidade que caracterizava sua nova condição, isto é, a de cristão-novo, o que segundo o autor, "o problema dos cristãos-novos, que oscilavam entre o judaísmo e o cristianismo, tornando-se, portanto suspeitos de heresia, irá perdurar por vários séculos ainda na sociedade espanhola" (MEZAN, 1974, p. 184). 
Em outra passagem, logo em seguida, surge a presença e a atuação da Inquisição sobre os cristãos-novos e o que ela representou nesse período, "para a História Judaica, a Inquisição é importante não só por ter matado judeus, mas por ser a causa indireta de sua expulsão da Espanha" (MEZAN, 1974, p. 188). Nesse pequeno trecho podemos perceber que a perseguição ocorria somente aos cristãos-novos e não aos judeus que "estavam fora de seu alcance" (MEZAN, 1974, p. 188).

Quando relata a expulsão dos cristãos-novos do território espanhol e sua chegada em Portugal, o autor evoca o início dos judeus na região, por volta do início do século XII, e, até se dar conversão forçada no ano de 1496, o território luso é descrito como "o asilo preferido pelos emigrados" (MEZAN, 1974, p. 190). Boa parte da narrativa é dedicada a relevância desses personagens para a Corte Portuguesa, não só pelos serviços médicos, ou cargos administrativos que exerciam, mas também pela participação que tiveram no empreendimento das Grandes Navegações:

Astrônomos como Zacuto e José Vizinho prepararam as tabelas celestes que os navegadores levavam consigo; outros construíram instrumentos mais aperfeiçoados, como astrolábios e sextantes, de grande utilidade para as viagens. Cartógrafos como Judá Cresques prepararam os mapas indispensáveis àquela (MEZAN, 1974, p. 190).

Chegando ao período que remete à conversão exercida por D. Manuel, o autor atenta para as profundas repercussões do episódio, refletindo inclusive, segundo ele, na história do Brasil, quando um grande número de cristãos-novos recebeu a concessão de monopólios reais, como Fernando de Noronha, que explorou o pau-brasil nos primeiros anos do século XVI (MEZAN, 1974, p. 191).

É a partir do 90 capítulo que Mezan, aprofunda sua narrativa acerca dos cristãos-novos no Brasil, referindo-se a eles como aqueles que colaboraram ativamente nos anos iniciais do povoamento da colônia. Sua escrita em torno dos cristãos-novos na América Portuguesa situou-se mais no período da ocupação holandesa, onde buscaremos tecer algumas considerações que possam esclarecer melhor o entendimento sobre a presença de tais personagens em nosso território sob o olhar de uma escrita judaica. 
Em sua descrição, os cristãos-novos aparecem como aqueles que atraídos pelo desenvolvimento da cana-de-açúcar, se inseriram na comunidade nordestina, envolvendo-se em várias atividades como a de soldados, desbravadores, capatazes, "um grupo dinâmico na sociedade colonial". A esse fato, o autor atenta para o olhar inquisitorial que passa a recair sobre o grupo, principalmente durante as visitações, acusando-os do ato de judaizarem, o que nos leva a afirmar que "o problema judaico não era desconhecido no Brasil" (MEZAN, 1974, p. 241).

Ao referir-se à construção da sinagoga Tzur Israel na cidade de Recife, Mezan (MEZAN, 1974, p. 242), não faz qualquer menção à tolerância religiosa de Nassau, como apontada pelos demais autores dos livros didáticos analisados no capítulo anterior. E acerca dessa temática, gostaríamos ainda de fazer alguns apontamentos, a partir de um estudo recente, de João Henrique dos Santos, que faz a seguinte observação:

Sob a égide do Regimento para as Praças Conquistadas e para aquelas que vierem a ser conquistadas, aprovado pelos EstadosGerais em 1629, era garantida a liberdade de prática religiosa nos domínios holandeses, desde que observadas as limitações a isto, conforme emanadas das autoridades da Companhia das Índias Ocidentais. Observa-se, portanto, que existia uma situação de liberdade concedida, não conquistada. Isso gerou a possibilidade de que os cristãos-novos residentes em Pernambuco pudessem voltar à prática do judaísmo, especialmente após terem contato com os judeus sefaradis, que, igualmente, também eram "gente da nação", que chegaram com os holandeses (SANTOS, 2009, p. 63).

A questão é que, como demonstrado na passagem anterior, o fato dos judeus poderem professar sua religião, não pode ser associado a uma questão de tolerância, tendo em vista que haviam limites para que a mesma fosse praticada. Também, ao que parece, esse Regimento não se aplicava somente aos judeus, mas também aos católicos quando em 1638, foram proibidas algumas de suas práticas, por parte dos holandeses, como, "as procissões e todas as manifestações externas de culto católico, assim como a proibição do casamento católico sem a licença da Igreja Reformada, a bênção dos engenhos por padres e a extrema-unção, por padre, dada a portugueses condenados à morte" (SANTOS, 2009, p. 61). 
Nas passagens retiradas das obras didáticas que aqui nos propusemos a analisar, verificamos outra visão sobre a prática do judaísmo, principalmente naquelas mais contemporâneas. A construção da sinagoga, por exemplo, está claramente relacionada a um ato de tolerância por parte dos holandeses, mais especificamente, do então governador Maurício de Nassau, o que contradiz a versão apresentada acima.

Sobre a "saída" dos judeus do Recife holandês quando os portugueses retomaram o território, o autor não comenta sobre os legados culturais e religiosos deixados por eles em nosso território, porém, enfatiza desde o início de sua narrativa o quanto sua participação naquela sociedade foi significativa, sob o ponto de vista econômico e social.

Outro fator que nos chama a atenção, é o relato do autor quanto à "saída" dos judeus do Recife holandês, segundo ele, a vida dos cristãos-novos que na região se encontravam passou a sofrer ameaças constantes por parte das perseguições movidas pela Inquisição, que naquele período, "tornaram-se mais suspeitos do que nunca de judaização" (MEZAN, 1974, p. 244). Na mesma passagem, a escrita revela o retorno de muitos cristãos-novos à sua antiga religião, o que explicaria a atitude da Igreja frente ao grupo.

A partir das passagens aqui discutidas, no que tange a presença dos cristãos-novos no Brasil colonial, Mezan, reconhece a atuação bastante diversificada dos neocristãos naquele tempo e espaço descrito por ele, dando indícios sobre a importância que tais agentes tiveram tanto na vida social, quanto econômica e religiosa daquela população, além da importância que os judeus tinham para a Corte Portuguesa e os conhecimentos desenvolvidos e aprimorados por eles durante as Grandes Navegações. Não menos importante, o autor também discute a atuação da Igreja Católica sobre a vida de tais personagens, que certamente não se restringia somente a eles, mas também aos escravos, judeus, e todos aqueles que agiam diferente dos dogmas cristãos. 


\section{O cristão-novo na cultura material escolar de Cheder: algumas considerações}

Embora nossa discussão não tenha como prioridade discutir acerca da escola que ora aqui escolhemos, consideramos pertinente a discussão de alguns aspectos quanto à sua organização, bem como os preceitos e valores que a constituem, para se pensar sobre o modo como o cristão-novo é abordado no material didático utilizado pelos alunos.

Nossa escolha partiu de um trabalho diferenciado que nos chamou a atenção, desenvolvido por uma das professoras que atuam na instituição junto ao LEI (Laboratório de Estudos sobre a Intolerância da USP). A professora atua como responsável pelo curso de Cultura Judaica no $8^{\circ}$ ano do Ensino Fundamental, e utiliza além do material solicitado pelo colégio, uma série de textos produzidos por ela, fundamentados em artigos, teses e dissertações disponibilizados pelo Laboratório. A intenção é propiciar mais um elemento a ser pensado no conhecimento histórico dos alunos acerca da Cultura Judaica, levando até eles uma escrita que passa por um processo de didatização, ou seja, numa linguagem acessível aos mesmos.

Fundado em 1943, por um grupo de imigrantes de judeus vindo da Europa, o colégio segue o modelo tradicional. Por ter surgido na década de 1940, a instituição acompanhou as mudanças sociais e políticas do país, de modo que suas estruturas administrativas e pedagógicas também passaram por modificações.

De modo geral, podemos afirmar que os próprios anseios da comunidade judaica estabelecida no Brasil frente às escolas judaicas também sofreram transformações. Essas por sua vez, fizeram surgir novas expectativas que ia além da formação dos alunos enquanto judeus, fato esse que levou à ampliação dos currículos, a fim de garantir um ensino de qualidade voltado para a preparação dos mesmos, tanto para a vida adulta, quanto para o mercado de trabalho.

Sobre essa questão, em nossas leituras, pudemos constatar a existência de controvérsias por parte dos vários membros da comunidade judaica quanto ao tipo de ensino a ser proporcionado para os alunos. Grinberg atenta para essa temática ao discutir sobre o papel da escola na construção da identidade judaica, 
identificando-a como um tema bastante polêmico entre os judeus. As dúvidas em relação a qual o melhor modelo de escola a ser oferecido aos alunos parecem oscilar entre a necessidade de coesão e manutenção da unidade pra continuidade do povo judeu e o exclusivismo que a convivência pode gerar. Outro aspecto seria a falta de interesse por parte de alguns alunos em relação às disciplinas relacionadas ao judaísmo, que segundo a autora, "as matérias judaicas são criticadas por não serem ensinadas de forma interessante e por não haver discussão atual acerca de Israel, embora as referências ao país sejam constantes" (GRINBERG, 1997, s/p).

O Cheder conta hoje com cerca de 800 alunos no total, que vão desde um ano e meio de idade - maternal - até o Ensino Médio. O programa adotado na instituição obedece às demandas do currículo oficial, bem como também procura atender os parâmetros judaicos, os quais se baseiam no modelo do programa de educação israelense que traduzido para nosso idioma seria "Educação para a diversidade" (GRINBERG, 1997, s/p, 81).

A partir do Ensino Fundamental até o Ensino Médio, predominam as exigências do currículo nacional, o que significa uma redução bastante acentuada se comparada com o que ocorria antigamente, e com os outros níveis de ensino, das aulas de Judaísmo. Quanto ao ensino do hebraico, constatamos que sua importância permanece como elemento indispensável na formação dos alunos judeus, uma matéria que faz parte do currículo escolar.

Essa e outras observações a respeito do tipo de ensino proposto pela escola judaica nos levou a compreender que se trata portanto, de uma cultura escolar dentro de uma outra cultura, constituindo assim, um sistema bastante complexo.

Num depoimento acerca de um equilíbrio entre tradição e modernidade, o professor João Carlos Martins, diretor geral do Colégio Renascença, entende que:

A modernidade não exclui a tradição, compreendida como os valores e as práticas que historicamente se perpetuam ao longo do tempo, e que permanecem nos dias atuais. Vivemos a modernidade na sua diversidade, fragmentação e pluralidade marcadas pela globalização, experenciando a rápida transformação - inclusive virtual - típica desse tempo (Tribuna Judaica, 2011, p. 11). 
Ao mesmo tempo, dando continuidade à forma como o colégio em que atua consegue conciliar tradição e modernidade, o professor deixa claro a complexidade com que se dá tal busca, em uma época que segundo ele, "a identidade judaica se tornou fragmentada e confusa" (Tribuna Judaica, 2011, p. 11).

Por essa razão entendemos que a escola judaica como um espaço de transmissão da cultura, religião e tradições judaicas e que ao mesmo tempo procura corresponder às especificações do currículo nacional, acaba de certo modo, umas mais outras menos, integrando-se com a "cultura circundante", conforme constatou Diana da Veiga Mandelert (2005). Em seu estudo acerca da escola judaica, mais especificamente de uma escola do Rio de Janeiro, a autora nos leva a crer que esta integração da cultura judaica com a cultura brasileira faz todo sentido, mesmo quando colocada numa perspectiva mais abrangente. Dentre as razões, que diferenciam a escola judaica das demais, "são as relações sociais, a orientação religiosa e o que podemos chamar de tradição familiar: os pais já terem estudado na escola" (MANDELERT, 2005, p. 84).

A forma como se da à organização curricular no Cheder, não parece muito diferente da maioria das outras escolas judaicas de São Paulo, ainda que existam umas mais ortodoxas que outras. A proposta um ensino de qualidade, que atenda as exigências políticas curriculares brasileiras e, forneça ao mesmo tempo condições para a manutenção da fé judaica, confirma nossa hipótese.

Os estudos que ora realizamos sobre a educação judaica no Brasil, mais especificamente no Estado de São Paulo, ainda que pautados no exemplo de uma única instituição, nos leva a crer que o fato das escolas judaicas apresentarem um currículo distinto, mas que não deixa de atender as demandas oficiais, acaba gerando um vínculo entre duas culturas que não pode ser ignorado, e que talvez, como concluiu Manderlet, "possibilita aos alunos sentirem-se judeus sem se sentirem estrangeiros" (MANDELERT, 2005, p. 76).

Esse currículo diferenciado deve ocorrer num horário também diferenciado das demais instituições, sendo integral em alguns dias da semana, mesclando dentre outros projetos, as disciplinas que compõe o currículo oficial, com aquelas que atendem a constituição de uma identidade judaica. 
Por meio das listas de materiais exigidas pelo colégio que nos propusemos a investigar, é possível verificar o modo como estão disponibilizadas as disciplinas, como por exemplo, do Ensino Fundamental II, que segue do $6^{\circ}$ ao 90 ano. Constatamos que ao lado daquelas que compõe a Matriz Curricular Nacional, em todas as séries, está aquela que engloba o curso de Cultura Judaica.

O material que ora focamos nossas análises, corresponde exatamente a esse último e na utilização dos textos que são elaborados pela professora responsável pelo curso junto ao LEI, e que por ela são trabalhados no $8^{\circ}$ ano do Ensino Fundamental.

No que se refere ao LEI, sua criação se deu no ano de 2002, pelo Departamento da USP, a partir de uma reivindicação da professora Dra. Anita Novinsky, importante colaboradora para o acervo documental que nele hoje se encontra, oriundo das pesquisas realizadas no Arquivo Nacional da Torre do Tombo, em Lisboa, no Arquivo Nacional de Madrid, Arquivo Histórico de Sevilha, na Biblioteca Rozenthaliana de Amsterdã, assim como do Arquivo Nacional do Rio de Janeiro e outros arquivos estaduais brasileiros. O período que remete aos estudos coloniais foi ampliado para o período moderno e contemporâneo, constituindo-se num espaço onde atuam pesquisadores que trabalham diferentes realidades espaço-temporais e múltiplos recortes teórico-metodológicos, além de uma diversidade de temas, a fim de dinamizar os debates sobre a Intolerância.

Dentre os objetivos do mesmo, se encontra a produção de materiais pedagógicos para as redes pública e privada do Ensino Fundamental e Médio, como ocorre com o material que aqui nos propusemos a analisar, elaborado e aplicado por uma professora que atua no colégio Cheder, voltado respectivamente para o $8^{\circ}$ ano. 0 acesso ao material nos possibilitou encontrar 0 cristão-novo numa perspectiva temporal e espacial mais abrangente do que aquela que outrora analisamos.

Comecemos nossa análise pelo texto $A$ Inquisição na Bahia. Logo no início da narrativa a autora faz questão de informar ao leitor sobre a origem dos cristãos-novos, quantos estavam estabelecidos na região, e também sua integração na sociedade, passando pelo processo de miscigenação. 
Depois, descrevendo as mais diferentes funções exercidas pelos cristãosnovos, a autora chama a atenção para a condição de cristão, à qual foram submetidos, e o quanto, pelo menos no setor econômico e social, podia lhes ser favorável. Referindo-se a esfera religiosa, a autora mostra que o mesmo não ocorria, o que levava à prática oculta do judaísmo, que logo passou a ser investigada pelos agentes inquisitoriais. Nessa altura do texto, é citada a Carta Monitória e a ameaça de uma possível instauração de um tribunal da Inquisição no Brasil, deixando claro para o aluno o clima de controle e vigia que se abatia sobre a vida dos neocristãos, principalmente quando ocorriam as Visitações e as prisões e mortes, em geral, nas fogueiras que acometeram alguns deles, ao serem enviados para Lisboa.

Interessante perceber que em seus relatos, a autora ao descrever as ameaças que sofriam e as práticas criptojudaicas que eram realizadas pelos cristãos-novos que não aceitavam a conversão, passadas pelos seus pais, dá indícios de que os judeus convertidos, não agiam como vítimas, mas ao contrário procuravam criar mecanismos de resistência que burlassem as medidas restritivas colocadas a eles, à sua condição, pela Igreja Católica.

Nesse mesmo contexto, é possível notar também, o bom convívio que existia entre os cristãos-novos e os demais habitantes da Bahia, exemplificandoo não só por meio dos casamentos mistos que lá ocorriam, como também pelos "laços de amizade".

Em Judeus, cristãos-novos e calvinistas durante a ocupação holandesa no Brasil, notamos que a professora preocupou-se em contextualizar o período que antecede a ocupação holandesa e também, depois, quando se deu a chegada dos holandeses ao Brasil. Sua narrativa inicia com a morte do Rei Sebastião, e no que isso acarretou para os portugueses, até chegar às razões que teriam atraído os holandeses para a Bahia primeiramente e depois para Pernambuco. A partir desse momento, surge o cristão-novo como colaborador do domínio da Holanda sobre o Brasil - alguns deles, como ela faz questão de informar - e o retorno dos mesmos para sua antiga religião. Os judeus de Amsterdã também aparecem, ao lado de outros soldados contratados para ajudar no plano de dominação, ao lado dos cristãos-novos enquanto financiadores da indústria do açúcar, e outras atividades que provinham da mesma. 
Ao descrever sobre os diversos setores em que a comunidade israelita atuou, judeus e cristãos-novos, e o modo como contribuíram para o desenvolvimento da região a autora possibilita ao aluno ter uma maior dimensão sobre a participação dos mesmos na sociedade que passaram a integrar e os legados por eles deixados, tanto na medicina, quanto a própria religiosidade, a engenharia, a advocacia.

Referindo-se à Rua dos Judeus que outrora identificamos na narrativa de alguns dos livros analisados no $3^{\circ}$ capítulo da pesquisa, a autora demonstra uma preocupação maior ao descrever a forma como esse bairro se constituía:

\begin{abstract}
A principal via de um importante bairro comercial foi nomeada de rua dos judeus, devido a grande variedade de estabelecimentos judaicos. Nesta rua, os judeus mais prósperos viviam em sobrados de dois andares, sendo o andar térreo o seu comércio e o segundo andar, a residência. A rua dos judeus era situada ao lado de uma bela praça e próxima da praia dos judeus. Foi nessa rua que foi construída a primeira sinagoga das Américas (LEVY, 2011, p. 4).
\end{abstract}

O texto em si não traz qualquer imagem sobre a rua a qual se refere a autora, porém, é possível ao leitor, pela descrição, imaginar como ela se organizava, assim como, a importância que o bairro representava para aquela sociedade naquele espaço de tempo; havia mais de um tipo de negócio, a economia não girava em torno de uma única atividade; havia uma diferença sócio-econômica entre os israelitas que ali se encontravam.

Outro fator que nos chamou a atenção na passagem acima, é quando a autora revela a existência de uma praia que ela afirma ser de uso exclusivo dos judeus e a sinagoga que também fora construída ali naquela região. Os detalhes apontados pela professora acerca da rua dos judeus certamente pode propiciar ao leitor uma reflexão sobre o quanto os chamados "Gentes da Nação" estavam inseridos na sociedade da qual passaram a fazer parte.

No texto Nas selvas brasileiras: marranos constroem as primeiras vilas de ouro (Minas Gerais - século XVIII), a autora traz os cristãos-novos logo no início da narrativa, como aqueles que atraídos pela descoberta do ouro teriam contribuído para a fundação das primeiras vilas da região, segundo ela: 
Tiraram sua subsistência do trabalho agrícola, da mineração e do comércio. Mantinham roças de mandioca, eram mineiros, negociavam ouro e pedras preciosas, havia alguns profissionais liberais, como médicos, mas principalmente, dedicaram-se ao comércio, trazendo para a região gêneros essenciais para a subsistência. Negociantes cristãos-novos da Bahia e do Rio de Janeiro enviavam "carregações" para as Minas. Alguns ali mantinham residência, deixando na cidade de origem suas famílias, indo e vindo entre a região e o litoral. Levavam pra lá vestimentas como chapéus, camisas, calções de pano de algodão; comerciavam panos de linho, aguardente, sal, açúcar, queijos, peixe seco, cavalos, gado e escravos (LEVY, 2011, s/p).

Como podemos perceber, a narrativa é bastante rica, no que se refere aos negócios realizados pelos neocristãos em Minas Gerais, levando o leitor a perceber as diferentes redes de relações que lá estabeleciam bem como sua importância para a economia local.

Baseando-se nos documentos a que teve acesso, a professora comenta no texto apresentado, a presença inquisitorial no solo mineiro e a dura perseguição sofrida pelos cristãos-novos no século XVIII. De acordo com sua escrita, a região teria sido a que mais forneceu cristãos-novos às fogueiras da Inquisição, ou porque já tinham sido acusados da prática do Judaísmo quando estavam em Portugal, como o caso do médico Diogo Correa do Vale citado por ela, ou pelas suas práticas judaizantes.

Outro fator que levava às condenações eram as ideias. Sobre essa última, é interessante perceber como a autora traz à tona duas questões que podem ser trabalhadas sobre diferentes enfoques, porém, num mesmo contexto. A primeira delas é a crueldade com que se davam os castigos impostos pela Igreja naquele período, como o caso de Diogo Nunes Henriques, preso e queimado no século XVIII por defender o direito de "igualdade de todos os homens". A outra seria a existência de uma mentalidade que destoava daquela da época. Segundo ela:

Os cristãos-novos não foram perseguidos somente por suas cerimônias religiosas, mas principalmente por suas ideias. Nas montanhas de Minas Gerais, Diogo Nunes Henriques foi preso no século XVIII por dizer que "cada homem era livre para adorar a Deus conforme sua consciência" (LEVY, 2011, p. 1).

O último texto o qual tivemos acesso para analisar o modo como se configura a presença cristã-nova na América Portuguesa, São Paulo Colonial e os 
Bandeirantes, o cristão-novo surge na figura de um personagem bastante conhecido de nossa história, José de Anchieta, um dos fundadores de São Paulo. A autora enfatiza a condição do Apóstolo de descendente de israelitas quando se refere à sua descendência materna e a seu trisavô queimado pela Inquisição acusado de judaizar. No mesmo contexto, a professora apresenta em sua escrita o Padre Leonardo Nunes, outro cristão-novo, responsável pela vinda de Anchieta ao Brasil, e que teve segundo ela, sua origem documentada, em uma carta de 1553 do Jesuíta Vicente Rodrigues endereçada à Companhia de Jesus, reclamando do grande número de neocristãos na Vila de São Paulo.

Mais a frente, a autora dedica sua escrita ao movimento das bandeiras, onde revela a possível existência de judeus entre os bandeirantes, como o caso de Raposo Tavares, que segundo ela:

Não sabemos se Raposo Tavares, com seus numeroso filhos, seguia as práticas judaicas no interior de sua casa em São Paulo, entretanto seu vínculo com o Judaísmo aparece claramente num diálogo com um jesuíta que lhe perguntou " a que título os paulistas faziam guerra aos índios", ao que respondeu "pelo título que Deus Ihes dava nos livros de Moisés (LEVY, 2011, p. 4).

Os jesuítas é quem levantavam suspeitas ao questionarem a atitude de alguns indígenas que "criados por esses portugueses (paulistas), guardavam o sábado como um dia de festa e comem carne durante a quaresma". Para explicar o comportamento da Companhia jesuítica em relação aos de descendência judaica, a autora atenta para uma política antissemita, incorporando-se a ela um racismo, que em suas leituras, teria levado à discriminação dos mesmos. Sobre essa relação conflituosa que no Planalto Paulista se estabeleceu, entre os portugueses moradores em São Paulo e os jesuítas, a ação inquisitorial não passa despercebida, ao referir-se a ela no tratamento desumano sofrido pelos acusados:

Essas acusações dos jesuítas podem ser melhor entendidas pelo fato de serem os jesuítas o braço da Inquisição no Brasil, a qual tratava com desumanidade e racismo os descendentes de judeus, de terem sido os portugueses de origem judaica os principais desbravadores do território colonial (LEVY, 2011, p. 3). 
Voltado para o curso de Cultura Judaica, a narrativa não aborda o bandeirantismo em si, como ele ocorreu e as conseqüências do movimento. Porém, em se tratando dos cristãos-novos, fica claro para o aluno o fato de que esses agentes estavam entre os fundadores de São Paulo, tendo sido perseguidos pela Inquisição, acusados de falsos cristãos.

\section{Considerações finais}

Sobre os excertos dos textos analisados aqui, entendemos que a presença do cristão-novo é bastante significativa. O fato de apontarem para os diferentes espaços e tempos que os neocristãos vieram a ocupar no Brasil colonial, demonstra o quanto foi de fato ampla e diversa sua atuação, não deixando dúvidas acerca das contribuições deixadas por eles na sociedade que aqui se formou.

Os exemplos em torno desses indivíduos em meio à população tanto da baiana, quanto de Pernambuco, São Paulo ou de Minas, perseguidos, presos e até no caso de alguns deles terem sido levados para Lisboa e queimados pelo Tribunal Inquisitorial, reafirmam o poder exercido pela Igreja Católica da época, ao mesmo tempo em que revelam as dificuldades encontradas pelos cristãosnovos em "burlar" o sistema.

Concomitantemente, a complexidade que sua própria condição trazia, ou seja, a de cristão-novo, também aparece nas narrativas apresentadas, especialmente quando trata do período que remete à ocupação holandesa, com a chegada dos judeus de Amsterdã e o reencontro com suas antigas raízes.

Ao final percebemos que a escrita da história em torno dos cristãos-novos nos textos aqui apresentados, demonstra a todo o momento o quanto esses agentes estavam integrados nas sociedades em que se inseriram, criando redes de negociação e sociabilidade com as populações locais, mesclando-se a elas, ocupando cargos de confiança e criando mecanismos de sobrevivência. 0 criptojudaísmo apontado é um exemplo claro que pode contribuir para que o aluno perceba de que maneira os judeus conversos conseguiram enganar e dissimular a fé que ora haviam sido obrigados a adotar. 


\section{Referências}

ASHERI, M. O judaísmo vivo: as tradições e as leis dos judeus praticantes. Rio de Janeiro: Imago Ed., 1995.

CYTRYNOWICZ, R. Cotidiano, imigração e preconceito: a comunidade judaica nos anos 1930 e 1940. In: GRINBERG, K. (Org.). Os judeus no Brasil: inquisição, imigração e identidade. Rio de Janeiro: Civilização Brasileira, 2005, p. 285-314.

. ZUQUIM, J. Renascença 75 anos/1922-1997. São Paulo: Ed.

Renascença, 1997.

FALBEL, N. Judeus no Brasil: estudos e notas. São Paulo. Humanitas: USP, 2008. Literatura ídiche no Brasil. São Paulo: Humanitas, 2009.

GRINBERG, K. A Construção da Identidade Étnica na Escola Judaica: um estudo de caso. In: LEWIN, H. (Org.). Judaísmo: Memória e Identidade. Rio de Janeiro: EDUERJ. 1997.

MANDELELERT, D. da V. Pais na gestão da escola: mudaram as relações? Uma análise sociológica de uma instituição judaica. Dissertação de mestrado em educação. PUC-Rio. Rio de Janeiro: 2005.

RATTNER, H. R. Tradição e Ruptura. A comunidade judaica em São Paulo. São Paulo, Ática, 1977.

SANTOS, J. H. dos. Existentes, mas não cidadãos: o status jurídico dos judeus no Brasil Holandês (1630-1654). In: LEWIN, H. (Org.). Judaísmo e modernidade: suas múltiplas inter-relações. Rio de Janeiro: 2009. Disponível em: www.centroedelstein.org. Acessado em: 22/12/2011.

TRZONOWICZ, A. S. M. Ledor vador: construindo identidades judaicas de geração em geração. Estudo exploratório de casos de famílias e escolas judaicas em São Paulo. Dissertação de mestrado em Educação. Universidade Estadual de São Paulo. São Paulo: 2006.

Recebido em 04 de julho de 2013. Aprovado em 13 de dezembro de 2013. 